\title{
Inquiry into the Conceptual Dimensions of Project Portfolio Management
}

\author{
Pedro Bruno de Souza ${ }^{\dagger}$ \\ PUC-Rio / BNDES \\ Jorge Carneiro ${ }^{\Omega}$ \\ PUC-Rio \\ Rodrigo Bandeira-de-Mello \\ FGV/EAESP
}

\begin{abstract}
Although much has been written about how to manage individual projects, there is still little guidance on how to evaluate the "quality" of project portfolio management itself, that is, the degree of "accomplishment" of the process by which the project portfolio is formed and run. This study addresses this gap by employing a qualitative approach to uncover managerial perceptions about what is encompassed by project portfolio management and how the this construct should be evaluated. By building from a review of the scant literature on project portfolio management, conversations with expert scholars on project management, interpretations provided by managers, and theoretical reflection by the authors of this study, it was possible to identify main aspects that seem to tap how the degree of "accomplishment" of project portfolio management can be conceptually defined and operationally measured.
\end{abstract}

Keywords: Project portfolio. Project portfolio management. Strategy implementation.

Received in 27/08/2014; revised in 17/09/2014; accepted in 26/01/2015; divulgued in 03/08/2015

\footnotetext{
*Author for correspondence:

$\uparrow$ Master

Institution: Catholic University of Rio de

Janeiro PUC-Rio e BNDES

Address: Avenida República do Chile,

100 Rio de Janeiro - RJ - Brazil

CEP 20031- 917

E-mail: pedrobbsouza@yahoo.com.br

Telephone: 21 98217-3237
}

\author{
${ }^{\Omega}$ Doctor \\ Institution: Catholic University of Rio de \\ Janeiro PUC-Rio \\ Address: Rua Marquês de São Vicente, \\ 225, Gávea, Rio de Janeiro - RJ - Brazil - \\ CEP 22451- 900 \\ E-mail: jorgemtc@iag.puc-rio.br \\ Telephone: 21 99163-4177
}

\section{$¥$ Doctor}

Institution: FGV-EAESP

Address: Rua Itapeva 47411 andar, São

Paulo - SP - Brazil - CEP 01332-000.

E-mail: rodrigo.bandeira.demelo@,fgv.br

Telephone: 1137997740

Note from the Editor: The article was accepted by Emerson Mainardes

\section{(cc) BY}

This article has a Creative Commons License - Attribution 3.0 Not Adapted. 


\section{INTRODUCTION}

$t$ has been recognized that there are differences between corporate objectives as stated in the formal strategic planning and those actually implemented in practice (HREBINIAK, 2005). As a result, planned strategies often become unrealized (MINTZBERG; WATERS, 1985). Porter and Montgomery (1991) have argued that companies have to be more effective in their ability to transform planning into action.

Likewise, Kaplan and Norton (1996) contend that firms usually find it easier to formulate their strategies than to make them happen in practice.

Planned strategies and their corresponding strategic objectives have to be detailed into action plans and corresponding projects. However, there is a gap between top-level executives, who formulate the strategic planning, and middle-level managers, who in fact run the projects that are expected to transform strategy into reality. Also, while several guidelines have been forwarded on how to conduct (complex) projects (e.g., KERZNER, 2003; MEREDITH; MANTEL, 2000; PMI, 2008), there is still little guidance on how to manage the full set of projects as an integrated whole (COOKE-DAVIES, 2002), whose parts should present mutual consistency and reinforcement, while respecting priorities and budgetary constraints. An unintended consequence of this state of affairs is that firms often do not seem to be able to properly select and prioritize the appropriate set of projects (GRAY; LARSON, 2005; MESKENDAHL, 2010; MORRIS; JAMIESON, 2005; SRIVANNABOON; MILOSEVIC, 2006a, 2006b) and to run these projects in an cohesive fashion in order to reach organization-wide objectives.

Shenhar (2004) argues that the project portfolio (hereinafter, portfolio) needs to be seen from a corporate perspective, not from an individual project basis. So, firms should not only be "doing work right", but also "doing the right work" (COOPER; EDGETT; KLEINSCHMIDT, 2000a). Thus, project portfolio management (hereinafter, portfolio management) becomes crucial as a way to avoid the quest for local "optimums" or for individual interests that could be detrimental to the whole (GRUNDY, 1998; NOBLE, 1999). Portfolio management should build the bridge between the organization's strategic objectives and the operational management of the set of projects that would expectedly turn those objectives into reality (LEVINE, 2005). While project management would be more operational in nature, portfolio management occupies a more tactical role, as illustrated in Figure 1. 


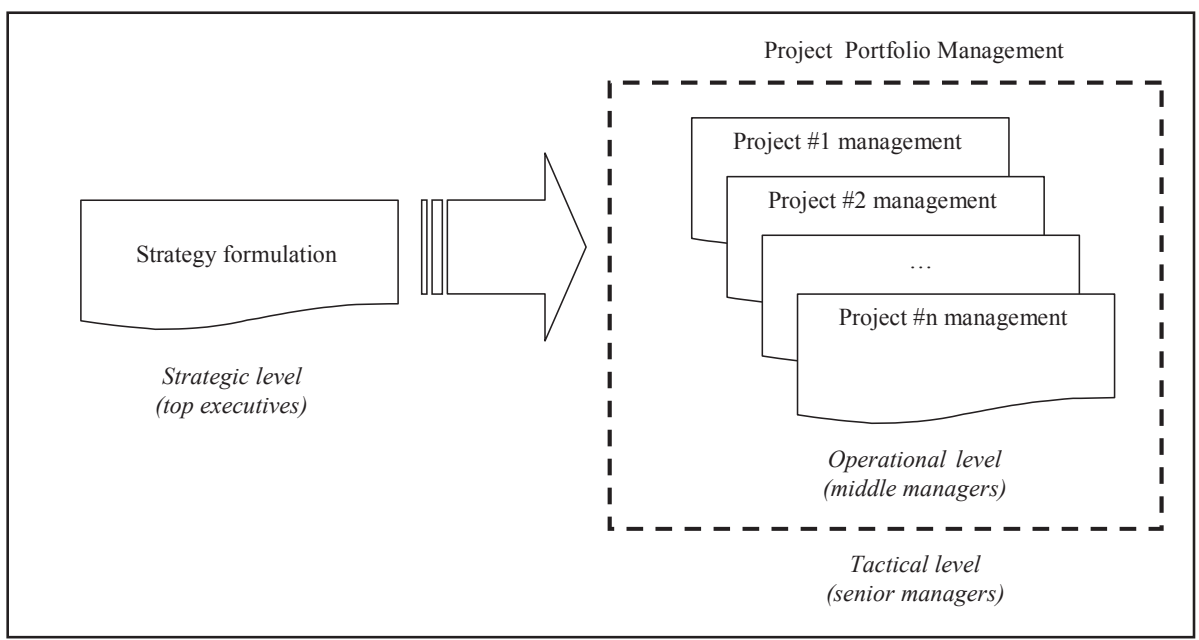

Figure 1 - The role of project portfolio management

According to PMI (2013),

Portfolio management is the coordinated management of one or more portfolios to achieve organizational strategies and objectives. It includes interrelated organizational processes by which an organization evaluates, selects, prioritizes, and allocates its limited resources to best accomplish organizational strategies consistent with its vision, mission, and values (p.5).

The lack of clear dimensions and indicators to characterize and measure the quality of project portfolio management is a gap, both in the academic literature (although the literature on individual project management is abundant) and in managerial practice. From a theoretical perspective it is important to understand the antecedents that would lead to good portfolio management as well as to understand the consequences of portfolio management, e.g., on a firm's performance and attainment of its strategic objectives, on employee satisfaction etc. From a managerial standpoint, it is important to count on guidelines on how to form and run a consistent portfolio of projects.

But, in order for researchers to test substantive relationships between constructs, first these constructs have to be conceptually defined and operationally measured in such a way that reflects their true nature and content domain. In Peter's (1981:133) words: "theories cannot develop unless there is a high degree of correspondence between abstract constructs and the procedures used to operationalize them". However, although quite a lot has been published (both in academic and business circles) on how to assess the performance of (individual) projects, the appropriate criteria to judge the quality of management of the portfolio should go beyond those employed to evaluate each component project. But the academic literature has been scarce as far as the conceptual definition and the operational measurement of the level of accomplishment of portfolio management is concerned.

This study contributes to the existing knowledge on portfolio management by 
pursuing the following research objective, which is relevant both from an academic and a managerial perspective: Unveil relevant conceptual dimensions of the (degree of) "accomplishment of portfolio management" construct, based in academicians' and practitioners' perspectives.

Our quest to conceptualize and measure the accomplishment of portfolio management is relevant because, as argued by Bible and Bivins (2012:10), although "[p]roject portfolio management (PPM) does not guarantee success in achieving strategic goals and objectives, [...] effective PPM process can increase the chances of selecting and completing the projects that best accomplish organisational objectives and contribute to achieving the organisation's vision".

\section{LITERATURE REVIEW}

\subsection{PROJECT MANAGEMENT AND PORTFOLIO MANAGEMENT}

According to PMI (2008), a project is a temporary endeavor with a defined beginning and end, which is directed to obtaining a new product, performing a service or attaining a specific result. Project management consists of the efforts to plan, obtain, organize and control resources, while complying with time and budgetary constraints, in order to achieve the goals of a specific project. Complementarily, portfolio management refers to the collective and integrated administration of a set of individual projects. Portfolio management is not an end in itself, but rather a means to attain of organizational objectives (MESKENDAHL, 2010; SHENHAR et al., 2001).

Building from Judgev and Müller's (2005:19) argumentation that "[p]roject management can have strategic value when a clear connection is made between how efficiently and effectively a project is done $[\ldots]$ ", one can say that portfolio management also involves efficiency (maximizing output for a given level of inputs) and effectiveness (achieving goals) concerns. There should be a distinction between short-term, project-wide, results (e.g., new product development) and longer-term, organization-wide, results (e.g., sales increase). Also, one should understand that there is a distinction (although also a close relationship) between success of portfolio management (i.e., administration of several aspects of the processes by which the portfolio is formed and executed) and success of the portfolio (achieving long-term business-wide results).

Several companies already follow guidelines for (individual) project management (e.g., those published by Kerzner, 2003; Meredith and Mantel, 2000; PMI, 2008). However, as organizations evolve in their maturity of project management, they find it increasingly 
important to establish procedures to manage, in an integrated fashion, the portfolio of projects (LEVINE, 2005). Levine (2005) and Meskendahl (2010) contend that portfolio management helps firms to bridge the abyss between organizational strategy and (individual) project management. Portfolio management combines (i) an individual project view to improve the effectiveness of each project with (ii) an organization-wide focus to select the appropriate set of projects according to the set of strategic objectives and collectively run them in an integrated and harmonic fashion.

PMI (2008:15) maintains that

[p]ortfolio management includes processes to collect, identify, categorize, evaluate, select, prioritize, balance, authorize, and review components within the portfolio to evaluate how well they are performing in relation to the key indicators and the strategic plan. During a typical business cycle, components will be reviewed and validated in relation to the following:

- $\quad$ Alignment of the components with corporate strategy

- Viability of the components as part of the portfolio, based on key indicators

- Value and relationship to other portfolio components

- Available resources and portfolio priorities

- Additions and deletions of portfolio components.

Dye and Pennypacker (1999) present the main differences between project management and portfolio management (Table 1).

Table 1 - Differences Between Project Management and Portfolio Management

\begin{tabular}{|l|l|l|}
\hline & \multicolumn{1}{|c|}{ Project management } & \multicolumn{1}{c|}{ Portfolio management } \\
\hline Objective & Resource allocation & Project selection and prioritization \\
\hline Focus & Tactical & Strategic \\
\hline Planning emphasis & Short-term (daily, weekly) & Long- and mid-term (quarterly, yearly) \\
\hline Responsibility & Project / Resource managers & Top managers \\
\hline
\end{tabular}

2.2 CONCEPTUALIZING AND MEASURING THE [DEGREE OF] ACCOMPLISHMENT OF PORTFOLIO MANAGEMENT

A proper theoretical definition of a construct should set the boundaries of coverage (what is encompassed by and what is excluded from the concept, albeit possibly related to it), identify the main distinct aspects (facets or dimensions) (BOLLEN, 1989) and also set an initial standard by which to select measures. Additionally a good definition should make clear the extent to which values of the construct are expected to differ across cases, conditions, settings and time (MACKENZIE, 2003).

The quality of portfolio management has been sometimes taken to be the degree of achievement of organizational objectives. But achievement of objectives (and also organizational performance for that matter) would be expected consequences of the management of the portfolio, but they would not be a constituent part of the "accomplishment of portfolio management" construct. In fact, from a theoretical standpoint, "a construct should 
not be defined solely in terms of its antecedents and consequences because the relation between the construct, its antecedents and consequences would be virtually validated (assumed to be true) by definition and thus would not be open for testing and refutation" (MACKENZIE, 2003, p.325). Besides, from a practitioner's perspective, the management of the portfolio has to be actionable by managers, so there have to be devised dimensions and metrics of the construct that are under the control of managers and which are defined prior to, and independently from, its consequences. In a related fashion, Cooke-Davies (2002:188) distinguishes between "project success (which cannot be measured until after the project is completed) and project performance (which can be measured during the life of the project)".

So, one should be careful not to confuse "accomplishment of portfolio management" with "success of the portfolio". Building from Cooke-Davies' (2002) arguments about individual projects, one can say that portfolio management differs from portfolio success, because the former involves basically the establishment of methods, procedures and techniques, while the latter may suffer the impact of changing organizational goals and of lack of cooperation from operational managers (who, in fact, execute the projects).

Literature is scant on how to measure the satisfactoriness of the management of a given portfolio. Some researchers have, nonetheless, proposed some general dimensions and metrics by which to conceive of and measure the degree of accomplishment of portfolio management. However, as will become clear, some of these dimensions seem to refer to either antecedents of the construct or consequences of it, but not really to the focal construct itself.

Some texts have just extrapolated from aspects to judge the performance of individual projects - e.g., financial success, technical performance (e.g., cost, quality, productivity, scope, innovation), customer satisfaction (and, in the case of new projects related to the development of new products, benefits accruing from new products) (ARTTO et al., 2008; COOPER, 2001) - to aggregates (across projects) of such measures. Shenhar et al. (2001) advocates similar metrics: project efficiency, customer impact, direct success on the organization and the business, and preparation for the future. Bible and Bivins (2012:10) explicitly argued that "[t]o assess performance at the portfolio level, it is vital to measure the performance of individual projects and consolidate the measurements in a mathematically meaningful way."

These metrics for the assessment of performance of individual projects are not enough, though, to measure the degree of success of portfolio management, since good (individual) project management is a necessary, but not a sufficient condition, for portfolio management 
success (DIETRICH; LEHTONEN, 2005; MARTINSUO; LEHTONEN, 2007). Besides, as previously argued, those measures just presented would, at most, refer to consequences of portfolio management, not to the construct itself.

As additional criteria to judge the performance of projects, Dai and Wells (2004) mention several "critical success factors" as predictors of performance: project mission, top management support, project schedule/plan, client consultation, technical tasks, communication to personnel recruitment/selection and training. But some of these items refer in fact to antecedents (predictors) of portfolio management (e.g., top management support) and not to the construct itself. On the other hand, Cooke-Davies mentions what he calls "success factors", which would be, in fact, determinants of success at the project level (e.g., adequacy of company-wide education on the concepts of risk management, and maturity of an organization's processes for assigning ownership of risks), but also some that could be considered indicators of accomplishment of (individual) project management (e.g., adequacy with which a visible risk register is maintained, adequacy of an up-to-date risk management plan, and adequacy of documentation of organizational responsibilities on the project) and which could inspire the proposition of dimensions to also judge the quality of management of a portfolio - but none refers to the conceptualization portfolio management itself.

Regarding portfolio management, Cooper et al. (2001) suggested that it would encompass three main goals: (i) value maximization (in terms of some business objectives, e.g., profitability), (ii) balance (in the variety of projects), and (iii) strategic direction (i.e., how well the "breakdown of spending across projects, areas, markets, etc., mirrors the business's strategy", p.15). Martinsuo and Lehtonen (2007) proposed five generic aspects of a construct that they called "project management efficiency" and defined it as "the organizational members' estimate of the degree to which the projects together, as a portfolio, succeed in fulfilling the portfolio objectives" (p.59): (i) portfolio-strategy alignment, (ii) knowledge of priorities, (iii) financial yield, (iv) realization of strategy, and (v) efficiency. Some of these aspects (e.g., portfolio-strategy alignment and knowledge of priorities) seem to relate to the conceptual frontier of what would constitute portfolio management, while the others would in fact be consequences of portfolio management.

Meskendahl (2010) contends that the main goals of portfolio management are: maximization of the financial value of the portfolio, linking the portfolio to the firm's strategy, and balancing the projects within the portfolio in consideration of the firm's capacities. Additionally, Meskendahl (2010) suggested that the degree of success of portfolio 
management should be assessed according to the level of achievement of four objectives: (i) average of single projects success (in terms of time, budget, quality, and customer satisfaction), (ii) use of synergies between projects, (iii) overall fit with firm's business strategy, and (iv) project balance.

Meskendahl (2010) deepens the discussion by proposing that portfolio success would depend on portfolio structuring, which would be composed of four aspects: (i) consistency ("the degree to which the strategic planning process forms the basic conditions for the portfolio and how closely strategic and portfolio planning are linked to each other”, p.812),

(ii) integration (between project management teams and other functional areas, i.e., the degree to which "the corporate functions concerned by the projects are adequately represented and to which extent they are involved in the portfolio decision process", p.812), (iii) formalization ("a rigorous, clear, and formal approach to portfolio selection [including] suitable and accurate data, explicit and objective criteria, reasonable and clear rules, transparent and known procedures", p.812), and (iv) diligence (how much "the portfolio structuring process is overall appropriate to select the 'right' projects [and] the degree to which scenarios are used, interdependencies are considered, and the mix of innovative and long-term projects is accounted for, is covered", p.812).

Miller, Martinsuo and Blomquist (2008), on the other hand, just argued for the use of multidimensional measures and multiple levels of analysis (project, portfolio and firm), but did not forward specific dimensions or measures. Cooper, Edgett and Kleinschmidt (2000b) argue that good portfolio management should consider: (i) allocation of resources, given that oftentimes there are too many projects and not enough resources (financial, human etc.), (ii) project selection methods, which should not only identify projects that pass the minimum "hurdle", but also rank projects against each other, (iii) collection of solid information in order to support managers' go/kill decisions early in the life of projects, and (iv) balance between "bolder" projects intended to transform the business and those intended to maintain or fix the business.

Bible and Bivins (2012) argued that key factors in attaining organizational objectives would include: (i) selecting the projects that best support strategic objectives, (ii) monitoring results along projects execution, and (iii) adjusting strategy and the portfolio according to strategic changes and need to get the results back on track as expected. Lacerda, Ensslin and Ensslin (2011) argue about the need to properly allocate resources (human, financial etc.) across projects and to communicate (although they mention only the project team, actually 
such communication should permeate the whole organization), and to monitor the execution.

The Enterprise Portfolio Management Council (2009) claims that successful portfolio management would include proper answer to five issues: investment in the right things (i.e., selection of the right processes), capacity optimization (i.e., balance between demand-side needs and supply-side offer of resources), execution quality, ability to absorb changes (i.e., flexibility and adaptation), and delivery of the promised benefits. PMI (2013) contends that the link between portfolio management and strategy would be attained by efforts in six areas: portfolio alignment, allocation of financial resources, allocation of human resources, allocation of material and equipment resources, measurement of the performance of portfolio components, and risk management. Also, portfolio management should include "processes to identify, categorize, monitor, evaluate, select, prioritize, balance, and authorize portfolio components within the portfolio" (PMI, 2013:21).

It should be noted, however, that some of these aspects proposed are in fact related to the consequences, or outcomes, of the process of managing the portfolio (e.g., value maximization, financial yield, and realization of strategy) and should not, from a strict conceptual standpoint, be included as aspects of the definitional domain of portfolio management. They are consequences of the portfolio management construct, not part of the construct itself. Nonetheless, they could be used, in a nomological perspective, to validate the conceptualization and operationalization of the construct.

On the other hand, some of the previously presented aspects seem indeed to compose the conceptual domain of portfolio management itself and may serve as a way to measure its accomplishment (i.e., how well was the project portfolio managed). For example, project evaluation, project selection, portfolio-strategy alignment, balance (among projects), synergy (among projects), prioritization, resource allocation, flexibility and adaptation, communication/integration across the organization, risk management, and monitoring.

Project evaluation should take in consideration how well each project scores in terms of criteria and metrics to judge the benefits of each individual project, as well level of risk, including cost risk, time risk and performance risk (COPERTARI, 2011). Lacerda et al. (2011) argue for a more formal and structured system (specifically, multicriteria decision aiding) for sorting and selecting projects to compose the portfolio and contend that the selection process should involve the establishment of evaluation criteria and the collection of information about projects. Oftentimes, firms end up with an active portfolio, composed of projects that get enough resources for immediate implementation, and a selected portfolio, 
composed of projects that will wait until resources become available. However, evaluating the attainment of goals at the individual project level is part of, but enough to, good portfolio management, since what counts is guaranteeing that the set of projects helps achieve organization-wide goals.

Project selection should aim at identifying "the combination of projects that provide maximum total relative benefit subject to the specified budget and organisational [resource] constraints" (BIBLE; BIVINS, 2012:12). Also, the selection should consider not only expected total benefits, but also level of risk. Selection criteria of individual projects to compose the portfolio should in fact consider evaluation, strategic alignment, synergy, balance and prioritization, as well as initial resource allocation.

Alignment with strategy means the degree to which each project and the set of projects reflect organization-wide strategic objectives and are expected to make them come true.

Projects can be of different natures and can be classified according to several criteria for example, functional area in the organization (e.g., IT, production, marketing, personnelrelated projects, to name just a few), role (e.g., maintenance, growth, transformation), level of risk, temporal horizon etc. Balance among the projects that are to compose the portfolio is in fact an input to the selection of the set of projects and would mean the achievement of some equilibrium or distribution across different types of projects, for example, (i) short- vs. longterm, (ii) low vs. high risk, (iii) new products, improvements, cost reductions, maintenance and fixes, and fundamental research (COOPER; EDGETT, 1997). Sound management of the portfolio should also aim at achieving a good balance between short- vs. long-term actions, between transforming vs. incremental actions, between risk and expected return across the set of projects and across functional areas within the organization - as well as a proper equilibrium between budgetary constraints and projects investment requirements. According to Levine (2005), a properly balanced portfolio should contain three types of projects: (i) mandatory (due to legislation) and devoted to maintenance; (ii) devoted to sustainable growth or organizational improvement; and (iii) transformation-related.

Synergy refers to integration across projects so that allocation of resources can be done in a more efficient way ( $c f$. AUBRY; HOBBS, 2001), either by sharing resources among projects or by improving project performance from the results of other related projects.

Prioritization refers to the assignment of the degree of relative importance to each project (with respect to the specific objectives they support and with respect to the overall 
goal, $c f$. BIBLE; BIVINS, 2012) and the decision about the timing and sequence in which they are going to be executed, based on organizational impact, level of change, and contribution to return on investment (ROI) (PMI, 2011). Bible and Bivins (2012) advise that some formal and structured system for scoring and ranking projects should be used to help select the projects that will compose the portfolio. Moreover, Copertari (2011) contends that projects may be

mandatory (they must be executed), mutually exclusive (either one project or the other is selected, but not both) or mutually inclusive (if A precedes B and project B is selected, project A must be selected first, but not necessarily the other way around, that is, project A could be selected without selecting project B) (p.11).

Initial resource allocation covers the criteria used to decide which and how much resources (financial, human, material) are to be designated to each project.

These aspects just presented refer to the formation of the portfolio. A complex picture emerges since such aspects and-are not independent.

Moreover, besides the formation of the portfolio, it is important to also consider the execution of the portfolio, once projects have been selected to compose it. This topic has also been tackled in the literature. Some of the component aspects of portfolio execution would include: risk management, flexibility/adaptation and resource reallocation, communication/integration and conflict resolution, and monitoring and follow-up.

Risk management should explicit identify "risks (positive/opportunities, negative/threats, internal, external [...] and how these risks impact the achievement of the strategic plan and objectives" (PMI, 2013:9), as well as maintain risk registers and an up-todate risk management plan.

Flexibility and adaptation (DVIR; LECHLER, 2004) involves additions and deletions (PMI, 2013) as well as modifications of portfolio components and is necessary in order for the organization to properly respond to changing external or internal conditions, modification of strategic objectives, cancelation or modification of poorly-performing projects, go/kill decision on an on-going basis (COOPER; EDGETT, 1997) and accommodation of more promising projects that might come along (PMI, 2013). Flexibility is particularly important given that "much of the information required to make project selection decisions is at best, uncertain, and at worst, highly unreliable" (COOPER; EDGETT, 1997:2), so criteria for resource reallocation across projects along the execution are necessary. Aubry and Hobbs (2011) address the dichotomy between control and flexibility and argue for the search of some equilibrium: "The PMO [project management office] participates in the line of control, giving 
the necessary stability [control] while at the same time encouraging innovation and change with flexibility" (p.7).

Communication/integration between the portfolio manager(s) and other organizational stakeholders is paramount in order to mitigate the danger of inadequate information and lack of visibility, as well as ensure legitimacy and access to organizational resources. Also, important is the adequacy of documentation of organizational responsibilities on the portfolio and on individual projects. Part of the communication function is to establish mechanisms for conflict resolution.

Monitoring partial results and close follow-up, together with flexibility / adaptation, are about observing the actual portfolio and deciding on necessary changes either to bring the portfolio back on track with the planned portfolio or to make changes to the planned portfolio as new information becomes available (MORGAN; LEVITT; MALEK, 2007).

It is interesting to note that the fact that some projects may be underperforming should not be immediately equated with poor portfolio management (although they may indicate low portfolio success), as long as managers monitor partial results and take corrective action. So, monitoring would be another aspect by which to judge the quality of portfolio management. Additionally, Aubry and Hobbs (2011) contend that the project management office should foster internal communication of project results to top-level managers and should have negotiation skills in order to resolve conflicts as projects advance.

It is clear that the conceptual mapping of the portfolio execution construct is complex, since several components of the construct are intertwined and may not simply be regarded as independent parts forming the construct; nor can they be treated as redundant or mutually substitutable manifestations of the construct.

Also, the frontier between the portfolio management construct itself and its antecedents and its consequences is not easy to draw. Whereas communication (of project results) can be argued to be part of the conceptual domain of portfolio management, capacity of negotiation could be seen as a determinant of the construct - at least of one of its facets, that is, the selection of projects to compose the portfolio - but a variant of it - conflict resolution - could be regarded as a constituent part of the portfolio management construct, as it would foster the continued development and execution of projects.

From our review of the literature, we preliminarily conceptualized portfolio management in terms of two broad "dimensions": (i) formation of the portfolio / selection of 
projects and (ii) execution of the portfolio. Each of these dimensions preliminarily encompasses the following components:

- Portfolio formation / selection of projects: assessment of strategic alignment, synergy assessment, ex ante evaluation of expected results, balancing, prioritization, and resource allocation;

- Portfolio execution: risk management, flexibility / adaptation and resource reallocation, communication/integration and conflict resolution, and monitoring.

This conceptual model is more comprehensive than what was presented by any single work in the literature and in fact integrates and consolidates several visions found in the set of works reviewed.

\section{METHODS AND DATA}

We develop a less prescriptive and more grounded conceptual model of portfolio management. While the literature offers interesting prescriptive models, the existing knowledge on how experienced managers actually organize this practice is rather scant. The development and refinement of a grounded model is important for both practitioners and researchers. While the former need to assess how well their firms are managing their portfolios, the latter are interested in developing and testing theories about antecedents and consequences of portfolio management (e.g., MESKENDAHL, 2010). The methods we use aim at unveiling relevant dimensions of portfolio management that will help define the content and frontiers of the concept (what is encompassed and what is excluded from it, $c f$. HINKIN, 1998).

Given the scant analytical literature on the conceptualization of the portfolio management construct (not to mention its operationalization), despite the existence of prescriptive models, we developed a grounded model following a mixed approach: taking the existing prescriptive models as point of departure, we interviewed a group of academic experts and experienced managers in portfolio management (as recommended by SUDDABY, 2006) in order to uncover aspects of the phenomenon and to assign meaning to the phenomenon as managers see it, not only as the researchers perceive it. We conducted semistructured, in-depth and open-ended, interviews in order to uncover informants' reports on good and bad practices they have experienced or know of. Questions requested examples and incidents of good and bad portfolio formation and execution, making explicit the elements (criteria and indicators) managers use to make this judgment. The comparison of good and 
bad incidents, coupled with our initial theoretical framework, helped us become sensitive to identifying and specifying latent dimensions of portfolio management (STRAUSS; CORBIN, 1998). This mixed inductive approach, which builds from the interplay between the vision of informants and the literature, seems appropriate given the complexity of the phenomenon under analysis (PATTON, 2002).

The informants were selected based on theoretical sampling (FLICK, 2006; STRAUSS; CORBIN, 1998) together with convenience sampling. We gathered a sample of senior project and portfolio managers and consultants, as well as researchers with academic background and/or academic experience in the field. This set of informants represents the experience of a wide variety of organizations, covering both public and private concerns as well as manufacturing and services industries of different sizes, and also encompasses both Brazilian firms and subsidiaries of foreign companies. We initially conducted 15 interviews to start our formal analysis. After six more interviews, we perceived only a marginal contribution to our unfolding dimensions, thus suggesting theoretical saturation. The final sample then consisted of 21 firms/interviewees.

Access to these persons was a big challenge. One of the authors is himself a project manager and used his network of Brazilian contacts (e.g., from communities of area experts, such as Project Management Office (PMO) Master Class) to recruit potential participants. In June 2011, he met several acquaintances at a PMO Master Class and explained to them the objectives of the study. A follow-up telephone or e-mail contact was used to schedule the interviews. We conducted 11 face-to-face interviews. Since informants were geographically spread in Brazil, we used telephone or Skype to gather the rest of the data. Interviews lasted 30-60 minutes and were recorded and transcribed for analysis. Data collection ranged from end-June until mid-July 2011. We assured confidentiality to respondents.

The interview script was pre-tested with two highly experienced managers in order to verify content adequacy and consistency in the understanding of the questions, as well as time to complete the interview. The guiding script of the interview was slightly refined along the first interviews, especially because the purposeful freedom of the interview led some participants to add relevant aspects that had not been anticipated by the researchers. We proceeded with caution to ensure data reliability. It is always a challenge to go beyond the 'institutional discourse' and the 'perfect story telling' told by managers about their organizations. They are often inclined to report success cases as well as not to dig deep into salient but sensitive issues. It was important, though, to get informants to address explicitly 
two different instances of portfolio management: one clearly successful and one not successful. We inserted this dichotomy in the research designed because we preferred not to assume that success and failure would be necessarily two extremes of the same continuum or that they could be conceived of and measured by the same metrics. In order to overcome social desirability bias, we avoided asking about incidents related to their present organizations, but rather asked them to talk about "cases you know of", or "organizations you know", or experiences they had been through in the their past professional lives. We also granted confidentiality to all informants. Since most of the cited organizations are wellknown, it was possible to partially triangulate the information using our knowledge about the company, and, when it was possible, cross-matching the data about a company cited by more than one informant.

We also implemented several procedures to enhance internal validity. First, each one of us independently analyzed all interviews in order to approximate an investigator triangulation (DENZIN, 2009). Second, constant comparison techniques, such as the flip-flop and the comparison with the existing literature (STRAUSS; CORBIN, 1998), helped us to verify our inductive insights. Finally, we applied the computer-assisted qualitative data analysis software ATLAS/ti in order to help us with the mechanics of coding, memoing, and representing our unfolding model in code-based networks, which is important to help sharing the results. At a final stage of the analysis, the Atlas/ti query tool contributed to build a more refined model as we 'attacked' our proposed model by systematically looking for incidents.

\section{FINDINGS}

\section{Sample characteristics}

Twelve interviewees worked for private firms and nine for state-owned organizations, representing a reasonable variety of business sectors: government, banks, consulting firms, IT services, food and beverages, energy, pension funds, mining and tobacco. Our final sample encompasses large organizations (more than 5,000 employees), mid-sized (1,000 - 5,000 employees), and small organizations (less than 1,000 employees). They had on average 6.2 years since implantation of a formal methodology of project management. About one third of our informants had more than 15 years of experience with project management, one sixth between 11 and 15 years, about one fourth between six and 10 years and another one fourth up to five years of experience. Nearly half of the respondents have graduate degrees in project management, including Master degree or Doctorate in the topic. One-third are instructors in project management classes and about two-thirds are PMI (Project Management Institute) 
certified. Half the respondents held senior responsibility over portfolio management in their organizations, about one-eighth were part of the portfolio team, one-fifth served as consultants in the area, and one-sixth occupied advisory positions to senior managers. So, informants can be regarded as knowledgeable enough and firms as experienced enough in project management for the purposes of this study. Along the presentation of the findings informants are identified as $\mathrm{P} 1, \mathrm{P} 2 \ldots, \mathrm{P} 21$.

\section{Unveiled dimensions of portfolio management}

Following a mixed approach, we developed the two categories proposed in our initial theoretical framework: portfolio formation and portfolio execution. As we kept them in mind, we were also sensitive to emerging concepts that could help us unveil the dimensions that characterize portfolio management for these managers. We now present the main results of this mixed approach. For each main category, we depict dimensions and implications.

\subsection{PORTFOLIO FORMATION}

Existing literature suggests that the formation of the portfolio should include project selection, assessment of strategic alignment, synergy assessment, ex ante evaluation of expected results, balancing, prioritization, and resource allocation. However, according to our informants, two of these activities are of major importance: the assessment of strategic alignment of the portfolio; and balancing and prioritizing projects. These two major activities resemble the aspects of portfolio formation that we could draw from the aggregate of the literature.

However, much as managers recognize the importance of portfolio formation as part of the process of managing the portfolio, some do not know how to measure how well portfolio formation is realized:

\footnotetext{
Some dimensions of the performance of portfolio formation are evaluated not with indicators, but with analysis, processes. There is not a concrete metric for that. (P12)

We do that [i.e., the assessment of the formation of the portfolio] not with an indicator, but as process of analysis. (P16)
}

\subsubsection{Strategic alignment}

Strategic alignment of the portfolio is the major activity of portfolio formation for these practitioners. It is at the core of project selection, as some excerpts show:

\footnotetext{
I think that the first criterion for successful portfolio is the assessment of strategic alignment. It does not matter who designed the strategy, but portfolio projects must the aligned with the company's strategy. (P1)

[...] if there is effective alignment between what the company has said about its strategy and what is happening at the operational level. (P5)
} 
However, one manager seems to have an opposite view:

I am fully against the establishment of 'strategic alignment' as a criterion for decision-making. [...] It is the opposite: the result of application of all criteria will tell you if that is aligned or not. Can you understand? (P22)

For the vast majority of managers interviewed, strategic alignment is a necessary condition for a the management of the portfolio to be judged as good and successful and is, thus, of central importance when forming the portfolio of projects. It involves not only coping with the technical appraisal of the portfolio outcomes, but also with the cognitive and political idiosyncrasies of the organization's top managers, as well as the level of formalization within the organization. Table 2 shows the conceptual aspects that characterize the strategic alignment dimension of portfolio formation, as they emerged from the interviews.

Table 2 - Conceptual Aspects of the Strategic Alignment Dimension of Portfolio Formation Category

\begin{tabular}{|c|c|c|}
\hline Dimensions & Description & Proof Quotes \\
\hline $\begin{array}{l}\text { Congruency } \\
\text { between firm } \\
\text { strategic } \\
\text { objectives and } \\
\text { portfolio } \\
\text { outcomes }\end{array}$ & $\begin{array}{l}\text { It captures whether the } \\
\text { (expected) benefits of the } \\
\text { completion of the portfolio } \\
\text { are related to the key } \\
\text { strategic objectives implied } \\
\text { in the company's strategy. } \\
\text { This dimension implies two } \\
\text { major practical worries: how } \\
\text { to measure ex-ante the } \\
\text { benefits of the portfolio } \\
\text { outcomes, and how to } \\
\text { separate the contributions of } \\
\text { each individual project. }\end{array}$ & $\begin{array}{l}\text { When you think about portfolio management, it is always } \\
\text { good to focus on one of these (objective types): investment, } \\
\text { capacity increase, market share. It is always a good } \\
\text { practice to identify and separate [these objectives] } \\
\text { because it will be helpful to propose metrics and } \\
\text { indicators of success accordingly (P9). } \\
\text { In terms of portfolio management the first managerial } \\
\text { activity of our office was to obtain the approval of the } \\
\text { committee based on the level of strategic alignment of the } \\
\text { cluster of projects: growth, capacity increase, productivity } \\
\text { improvement. For each type of cluster, we assessed } \\
\text { whether it contributes to the strategic objectives in order } \\
\text { to develop indicators (P11). }\end{array}$ \\
\hline $\begin{array}{l}\text { Cognitive and } \\
\text { political aspects } \\
\text { underlying top } \\
\text { managers' } \\
\text { perceptions }\end{array}$ & $\begin{array}{l}\text { This dimension reflects the } \\
\text { issue of getting support for } \\
\text { portfolio management. How } \\
\text { top managers perceive the } \\
\text { portfolio management itself } \\
\text { and how they agree to } \\
\text { classify and compose the } \\
\text { portfolio is important for the } \\
\text { interviewed practitioners. } \\
\text { This issue goes beyond the } \\
\text { competence for } \\
\text { implementing technical tools, } \\
\text { but rather, it requires good } \\
\text { political skills for the } \\
\text { portfolio manager. }\end{array}$ & $\begin{array}{l}\text { The first obvious key aspect for a good portfolio is the } \\
\text { issue of sponsorship. Portfolio management is absolutely } \\
\text { influenced by the top management team (P10). } \\
\text { It [portfolio management] a more political than a } \\
\text { technical job. The technical aspects that are often found in } \\
\text { the textbooks or guidebooks are easy to implement. How } \\
\text { do I prioritize projects? I use the added value risk matrix. } \\
\text { Ok, cool, but how to convince the guys at the top } \\
\text { management team. This is complicated! (P2). }\end{array}$ \\
\hline
\end{tabular}




\begin{tabular}{|l|l|l|}
\hline $\begin{array}{l}\text { Formalization } \\
\text { degree of the } \\
\text { company's } \\
\text { strategy }\end{array}$ & $\begin{array}{l}\text { The level of formalization of } \\
\text { the organization's strategy is } \\
\text { essential to evaluate portfolio } \\
\text { alignment (with strategy) as } \\
\text { it helps to make clear which } \\
\text { projects should be (or should } \\
\text { not be) in the portfolio. }\end{array}$ & $\begin{array}{l}\text { [in order to assess the strategic alignment], we always } \\
\text { seek to tbe aligned with the company's mission and vision } \\
\text { statements, as it is explicit in our Balanced Scorecard and } \\
\text { strategic maps (P3). }\end{array}$ \\
& $\begin{array}{l}\text { It is impossible to do any kind of portfolio management if } \\
\text { the organization does not have a formal strategy, explicitly } \\
\text { communicated and deployed down at the organizational } \\
\text { levels. If this strategy does not exist, it is too complicated } \\
\text { [...] We are going to have projects in our portfolio, } \\
\text { indeed, but they do not reflect what the organization really } \\
\text { needs, but only political and individual interests (P10). }\end{array}$ \\
\hline
\end{tabular}

The first aspect (congruency between firm strategic objectives and portfolio outcomes) connects the organization's objectives with the aftermaths of the project portfolio. Our interviewees agreed that the portfolio is not a homogeneous entity. It is composed of clusters of projects, each one assigned to one or more corporate objectives. However, two major practical problems arise from this connection. The first problem is to assess, prior to and after the formation of the portfolio, the aggregate (expected and attained) benefits resulting from the outcomes of projects composing each cluster in the first level and the portfolio as whole in an upper level. Each individual project may have its deliverables, but whether the aggregate of the chosen projects will in fact help the organization achieve its strategy is a hard task for managers. This is what they called 'post-project evaluation'. The challenge is how to decide which projects should be included based on ex-ante post-project evaluation, in order to achieve synergy among projects and alignment with strategic objectives:

The business case is not always measured within the time frame of the project, since the benefits of the project deliverables may happen afterwards. For the completion of the project, we rely on usual metrics such as budget, time and scope, but we need indicators that are able to capture these post-project benefits, or a 'post-morten', or post investment review. (P7)

The other practical challenge is precisely to disentangle the contribution of each project to the overall portfolio benefit. If one takes the interaction between project, cluster of projects within the portfolio, and the portfolio levels, the assessment of each project to choose based on the overall portfolio-strategy alignment becomes cumbersome. Managers in our sample struggled with this challenge and highlighted how important it is to correctly evaluate each project's contribution:

A way to assess the performance of portfolio management could be the alignment of the portfolio with the strategy. This alignment has to be complete. If there is one element in your portfolio that does not help your strategy, there are only two options: either strategy is wrong or that element is wrong. (P6)

We moved from a simple 'touch' in the strategic objective to a model in which, at the moment one was filling up the project proposal, he would have to point to the 
strategic objective and to the performance indicator of this objective that the project would be contributing to - as a way to ensure alignment. (P21)

What you can measure is this: "I increased my market share... I increased my profit". But what is the contribution of that specific investment? So, when you plan and say "this investment [project portfolio] will increase my EBITDA", what is the contribution of this specific project for building new plants and increasing capacity? Furthermore, the world will not behave as you envisioned during the planning stage. (P2)

The second conceptual aspect (cognitive and political aspects underlying top managers' perceptions) for the assessment of strategic alignment unveils the cognitive and political facets underlying top managers' actions towards portfolio management. One common aspect important to the practice of portfolio management is the required political capability of the portfolio manager. Running a single project may require technical capabilities, but running a portfolio requires political capabilities. The application of the technical toolbox does not seem to discriminate between successful and unsuccessful portfolio management. It is a quest for organization-wide legitimacy of the process of portfolio formation:

We succeeded in developing a formal process for project selection and prioritization. This process is accepted and then sponsored by the top management. (P12)

Criteria for judging a successful portfolio? The capability of implementing decisions. The issue of power is connected here. (P6).

Interestingly, although political capabilities are deemed important to the formation (and then, the execution) of a good portfolio, it is unclear whether political abilities should rather be considered an antecedent of portfolio formation instead of a constituent part of its conceptual domain map.

Finally, the third conceptual aspect of strategic alignment is the formalization degree of the company's strategy. Formalization involves clear registration of the firm's strategic objectives and goals and dissemination of this information to those responsible to form the portfolio. Having clear strategies is important for the assessment of the strategic alignment:

This is critical point. We tried to form the portfolio looking at the Government for the Integrated Development, which is a 20 -year strategic plan for the State. (P8)

Again, There is blurred view about whether the formalization degree of the company's strategy is actually a conceptual aspect of strategic alignment (and, therefore, of the portfolio formation category) or rather an antecedent to it. Either way, it is not possible to define alignment with strategic objectives if such objectives are not clearly defined (or communicated).

It is easy to note that these three dimensions relate to one another. In fact, formal strategies may reduce conflict and make explicit top managers' espoused cognitive schemas 
and political interests. By the same token, formal strategies may help select project types according to explicit corporate objectives.

\subsubsection{Balancing and prioritizing}

The second activity related to portfolio formation is the process of balancing and prioritizing the portfolio projects. Table 3 describes each conceptual aspect of this activity.

Table 3 - Conceptual Aspects of the Balancing and Prioritizing Dimension of Portfolio Formation Category

\begin{tabular}{|c|c|c|}
\hline Dimensions & Description & Proof Quotes \\
\hline $\begin{array}{l}\text { Projects and } \\
\text { resources across } \\
\text { strategic } \\
\text { objectives }\end{array}$ & $\begin{array}{l}\text { Connects balancing and prioritizing } \\
\text { across the strategic objectives in } \\
\text { terms of amount of required } \\
\text { resources and the number of projects } \\
\text { per strategic objective. }\end{array}$ & $\begin{array}{l}\text { The portfolio balancing based on the strategic } \\
\text { objectives takes into account the number projects } \\
\text { for each objective (P12). } \\
\text { We need to develop a better way to discuss resource } \\
\text { availability implications at the portfolio level and } \\
\text { not only at the project level. Depending on the } \\
\text { limitations of this or that area, this or that project is } \\
\text { postponed (P11). } \\
\text { For each objective I verify how many projects I } \\
\text { have. This is balance of the portfolio according to } \\
\text { the strategic map (P15). } \\
\text { One of the reasons we can say that the process was } \\
\text { not doing well it that we saw some strategic } \\
\text { objectives with five or six projects and some with } \\
\text { none. And they were important strategic objectives. } \\
\text { This means that a proper balance of projects had } \\
\text { not been done (P3). }\end{array}$ \\
\hline $\begin{array}{l}\text { Resources across } \\
\text { project categories }\end{array}$ & $\begin{array}{l}\text { Allocation of resources should be } \\
\text { balanced across project categories } \\
\text { (or, in some cases, according to } \\
\text { mandatory social obligations) and } \\
\text { strategic intents. }\end{array}$ & $\begin{array}{l}\text { According to the distribution model for our } \\
\text { portfolio, there are the 'structuring' projects, the } \\
\text { 'market opportunity' projects, and the 'global' } \\
\text { projects (P9). } \\
\text { For our categories, we established four categories: } \\
\text { growth, support, efficiency and process integration } \\
(P 11) \text {. }\end{array}$ \\
\hline $\begin{array}{l}\text { Resources across } \\
\text { projects }\end{array}$ & $\begin{array}{l}\text { The amount of required resources for } \\
\text { each project with respect to the total } \\
\text { available resources is an important } \\
\text { variable for managers in their } \\
\text { activity of balancing and prioritizing. }\end{array}$ & $\begin{array}{l}\text { Resource management for each project is very } \\
\text { important. One is very likely to miss good strategic } \\
\text { opportunities when there is no resource available } \\
\text { for some specific projects (P10). } \\
\text { Even if the project selection is good, we face very } \\
\text { complicated conflictual situations concerning } \\
\text { resource allocation across projects [...] it is always } \\
\text { very awkward to restore control! (P13). }\end{array}$ \\
\hline
\end{tabular}


Balancing and prioritizing projects in a portfolio seems to be more technical than assessing the strategic alignment. For the managers in our sample, it is about maximizing resource efficiency for attaining strategic objectives. The idea of resources is explicitly taken into account by the required resource deployment dimension. Balancing and prioritizing is strongly related to bargaining for resources. When the top management changes the resource availability, re-balancing and re-prioritizing are needed, which it is a fertile land for conflict.

The activity of balancing and prioritizing is related to the categorization of projects (e.g., maintenance vs. growth projects, short- vs. long-term, high vs. low risk). Managers reported different typologies for classifying projects and stressed the need to properly balance across projects:

In order to balance our projects, we use the Gardner methodology that classifies projects in "run", "grow", or "transform". (P9)

We need to think about how balance the results we want. We have few [limited] resources and several objectives! If we make some sort of prioritization during the planning stage, we are more likely to have a successful portfolio because we can use these resources more efficiently. (P8)

Besides, managers also emphasized that no strategic objective should be left without projects (and respective resources) assigned to it and that there should be some satisfactory balance between the number of projects and the amount of resources allocated across strategic objectives.

All in all, one has to balance and prioritize (i) projects and resources across strategic objectives, (ii) resources across project categories, and (iii) resources across projects.

\subsection{PORTFOLIO EXECUTION}

The second main category in our analytical framework is project execution. It refers to the structure and process required for the actual implementation of the projects within the portfolio. Table 4 shows the dimensions of this category that stemmed out of the interviews. 
Table 4 - Dimensions for the Portfolio Execution Category

\begin{tabular}{|c|c|c|}
\hline Dimensions & Description & Proof Quotes \\
\hline $\begin{array}{l}\text { Portfolio } \\
\text { management } \\
\text { structure }\end{array}$ & $\begin{array}{l}\text { Includes competences of the } \\
\text { portfolio manager and the portfolio } \\
\text { office structure and governance. }\end{array}$ & $\begin{array}{l}\text { I think it is important to talk about the } \\
\text { competences of the portfolio manager [...] } \\
\text { because these are rather different from those of a } \\
\text { more technical PMO. We are closer to business } \\
\text { [strategy].It is not only monitoring time and cost, } \\
\text { but it is a PMO that needs to talk the business } \\
\text { language (P4). } \\
\text { In a usual project selection process, we have } \\
\text { candidates and there is the committee who } \\
\text { qualifies which candidates will be prioritized. } \\
\text { [This qualification] analyzes the strategic } \\
\text { objective and the content. There is however a } \\
\text { previous technical analysis, when this technical } \\
\text { team indicates the resources and costs for each } \\
\text { project (P13) }\end{array}$ \\
\hline $\begin{array}{l}\text { Flexibility- } \\
\text { adaptation and } \\
\text { resource allocation }\end{array}$ & $\begin{array}{l}\text { How the organization organizes } \\
\text { itself to better use available } \\
\text { resources and how it copes with } \\
\text { changes and unintended } \\
\text { consequences. }\end{array}$ & $\begin{array}{l}\text { In many cases there are, within each project, } \\
\text { activities that could be jointly executed, } \\
\text { generating economies of scale. Purchasing, for } \\
\text { instance, is one of these activities that, if not well } \\
\text { organized, we cannot get good prices in a bid } \\
\text { (P3). } \\
\text { I monitor if the portfolio is being executed } \\
\text { following our planned budget. However, it is been } \\
\text { three years now, that we developed a } \\
\text { methodology to take into account not only the } \\
\text { planned average budget but also its variance } \\
\text { (P12). }\end{array}$ \\
\hline $\begin{array}{l}\text { Communication- } \\
\text { integration, conflict } \\
\text { resolution and } \\
\text { learning }\end{array}$ & $\begin{array}{l}\text { How the organization is solving } \\
\text { conflict among projects in a } \\
\text { portfolio and how it is organized to } \\
\text { learn from management of the } \\
\text { portfolio. }\end{array}$ & $\begin{array}{l}\text { In [the project of] using on-board computers in } \\
\text { police cars [...] the police board unilaterally } \\
\text { selected a technology without consulting the } \\
\text { police officers. After the implantation of this } \\
\text { equipment, nobody was using it! The project was } \\
\text { terminated (P1). } \\
\text { [The portfolio management] gave us the } \\
\text { opportunity of benefiting from lessons learned, } \\
\text { that is, how the organization is capable of } \\
\text { communicating these lessons to incur in fewer } \\
\text { errors in the future (P4). }\end{array}$ \\
\hline
\end{tabular}




\begin{tabular}{|c|c|c|}
\hline $\begin{array}{l}\text { Achievement of } \\
\text { result at the project- } \\
\text { level and the } \\
\text { portfolio level }\end{array}$ & $\begin{array}{l}\text { Captures the complexity of } \\
\text { measuring portfolio results, } \\
\text { particularly because of the large } \\
\text { number of interactions (positive and } \\
\text { negative) among projects in the } \\
\text { portfolio and the different degrees } \\
\text { of critically of individual projects to } \\
\text { overall portfolio results. }\end{array}$ & $\begin{array}{l}\text { Sometimes I can find instances in which a project } \\
\text { is out of bounds in terms of budget, but I have } \\
\text { other projects in my portfolio that are able to } \\
\text { balance the overall cost for the portfolio... [on } \\
\text { the other hand,] the fact that some portfolio } \\
\text { projects are green [i.e., on time and within the } \\
\text { budget] does not imply that you are in fact } \\
\text { implementing the strategy and will attain } \\
\text { corporate objectives. It is really difficult to find } \\
\text { indicators that grasp this complexity (P10). } \\
\text { We monitor the extent to which the number of } \\
\text { interferences [when the activities of a given } \\
\text { project negatively influence those of other } \\
\text { projects]. The fewer the better (P12). } \\
\text { There are no metrics to evaluate the success of } \\
\text { the portfolio today in my company. [...] what we } \\
\text { do is to see how the evaluation of each individual } \\
\text { project is done. We present a consolidated result } \\
\text { of the portfolio. But in fact the result that is being } \\
\text { evaluated is the sum of the individual } \\
\text { performance of each project. So there is not such } \\
\text { a metric to assess the portfolio (P10). } \\
\text { This is a vanguard theme because it is complex. It } \\
\text { is complex to measure, after it [the portfolio] is } \\
\text { ready, whether it was successful or not (P16). } \\
\text { Now, after the project is concluded, the new } \\
\text { factory starts its operation, the line is } \\
\text { modernized, the business landscape is complex, } \\
\text { so it is difficult to measure how [each of] those } \\
\text { projects [is] are contributing to revenue increase } \\
\text { (Pl6). }\end{array}$ \\
\hline
\end{tabular}

The first dimension of portfolio execution refers to the organizational structure responsible for managing the portfolio. It comprises how the tasks are divided among organizational departments or committees, how decisions take place and the distribution of authority. Included in this dimension is a particular mention to the competences of the portfolio manager in coping with this structure. One of such competences, besides being a political person, is the ability to manage multilateral decisions. As one of managers made it explicit: 
It is important that decisions [concerning portfolio management] are multilateral. In other words, it is the idea of portfolio management boards or committees. They are the ones that make the decision: go on, pause, resume, cancel, include. Unilateral decisions may jeopardize portfolio execution. (P10)

A well-defined governance is important to manage conflicts that are common in portfolio management. Conflicts during portfolio execution arise mostly when the organization needs to adapt to new resource allocation decisions. Communicating espoused criteria is important to mitigate bargain and integration conflicts. These two features flexibility to adapt and conflict resolution - are two other dimensions pertaining to portfolio execution. The result of both dimensions is the implicit learning dimension. Organizations that are able to integrate and better monitor conflict resolutions may be better learners. As in a virtuous circle, shared lessons will help improve better adaptation for resource allocation.

We need to know how to identify a good experience and try to share it with other portfolios. This share of experiences is a very hard task, but one of the most useful that portfolio management needs to implement (P3)

Finally, one of the most intriguing features of portfolio execution is that there is a complex interaction between the results (e.g., cost, time, scope attainment) of individual projects in the determination of overall portfolio results. This interaction may generate good and negative effects, which the interviewees called synergies or interferences, respectively and, taken together, results of individual projects may compound or cancel out. The number of possible interactions makes it extremely difficult for managers to assess actual portfolio results. Some managers suggested indirect indicators to complement usual indicators, as well as the avoidance of simply summated indicators.

As for monitoring the results, it is two sides of the same coin. There is the monitoring of the portfolio to assess whether it is following time, costs, and all that stuff we know. But we need to remember that the performance of the portfolio is not simply the sum of the performance of each individual project. I may have two projects with schedule problems, but they may not impact the overall schedule of the portfolio. (P10)

What would make my portfolio turn red? This is the big question. But they forget that what makes the portfolio turn red is not the situation of each project [...], but the risk of not fulfilling a strategic objective. In other words, I may have one project in red, but that does not [necessarily] mean that the portfolio is in red. Take time as an example. Maybe this project is red because it in fact is delayed. But if you see the entire portfolio, that single delayed project does not put at risk the time for my strategy $[\ldots]$ because it is not a critical path. [...] The same applies to cost. Sometimes one project may be beyond the budgeted cost, but I have other projects in the portfolio that can balance the total cost that was estimated for that portfolio. The same situation is true for the risk. There are important risks for each of the projects that are absolutely irrelevant to the portfolio. On the other hand, there are risks that cannot be identified within the project, but they are related to the portfolio as a whole. (P12) 


\subsection{ANTECEDENTS AND CONSEQUENCES OF (THE “ACCOMPLISHMENT” OF) PROJECT PORTFOLIO MANAGEMENT}

When prompted to talk about what would constitute good or bad (satisfactory or unsatisfactory) portfolio management, informants mentioned some variables that do not, in fact, characterize the management of the portfolio per se, but rather refer to aspects or circumstances that could affect how the portfolio is built or run. Some of these variables might be necessary, though not sufficient, conditions for the success of portfolio management. As such, they could be considered antecedents or determinants of the degree of success of portfolio management, but they are not part of the conceptual definition of the construct. The specific variables mentioned by the interviewees were: governance structure of the process of portfolio management, (successful) process of strategic planning, sponsorship, convincing power / relationship with others, good-quality and reliable databases, competence of the project management team, communication skills, establishment of project management methodology before the implantation of portfolio management.

Much by the same token, several interviewees mentioned variables that are in fact results, or consequences, of portfolio execution - for example, benefits attained, objectives achieved, effectiveness. These variables are not part of the conceptual domain map of portfolio management, although one would expect that the higher the level of accomplishment of portfolio management (conceptualized and measured by variables that are definitionally independent of the consequences), the better the results reached.

The main difficulty of organizations, and their main wish, is monitoring the achievement of benefits expected from the portfolio. OK, the project has come to an end, the portfolio has been executed, but who is in fact checking to see whether the benefits that we expected from this portfolio actually have been achieved or not? Are we reaching the strategies we imagined? (P21)

Moreover, some results may only become visible much after the portfolio has be run (managed):

[...] the most important and most difficult [task] is to monitor the benefits of the portfolio. [...] what do I expect from these projects, these set of projects? Ah, I expect an increase in market share, I expect some cost reduction, I expect an increase in revenues. This is the most difficult to do for various reasons. First because you do not see that on the same day that the project is finished. (P21)

This discussion makes it clear that the conceptualization and measurement of the focal construct - in this case, project portfolio management - has to be done independently of its (expected) antecedents and consequences, even if managers may confuse them by inadvertently equating portfolio success (i.e., attainment of objectives) with level of success of the portfolio management process: 
The portfolio is there to meet a strategic objective. If this objective is achieved, the portfolio is successful. This is the number one criteria of success of a portfolio. (P9)

\title{
4.4 MANAGERS' VIEW ON HOW TO MEASURE THE DEGREE OF ACCOMPLISHMENT OF PORTFOLIO MANAGEMENT
}

Some interviewees recognized the complexity in measuring the success of the process of portfolio management:

\author{
I think that this is the big bottleneck: how to measure the performance of portfolio \\ management. (P2) \\ So, what would be the criteria? This is not clear to me. (P7)
}

Managers do not seem to have a unified conceptualization of what should be included as part of the measurement of the degree of accomplishment of portfolio management. Some emphasize the macro-process of the formation of a portfolio from a set of projects; others focus on monitoring the execution of such portfolio; while for others what counts is the results obtained after the execution of the portfolio.

\section{DISCUSSION}

Three main inferences can be derived from our findings:

- managers do not clearly know how to draw the frontiers of what should be included in (and excluded from) the assessment of the (accomplishment of) portfolio management;

- (as a consequence) there is great diversity about how to measure the degree of success (or failure thereof) of portfolio management and very little formal guidance;

- firms seem not to have reliable and structured databases from where to collect information to assess the success of the portfolio, much less of the level of satisfactoriness of the process of portfolio management;

All in all, our provisional conceptual aspects related to the formation of the portfolio also emerged from the managers' reports. However, regarding evaluation of results, while some managers explicitly addressed the importance of an overall, portfolio-wide, ex post assessment, rather than just individual project ex post assessment, but few mentioned an ex ante evaluation of portfolio-wide (expected) results as an input to the formation of the portfolio; however assessment of synergy across projects partially tackles such ex ante overall assessment.

Managers have also addressed the measurement of company's results as a way to judge 
the performance of a portfolio. This point deserves a careful discussion. While it is clear that a portfolio of projects is put in place in order for the firm to achieve its strategic objectives, the measurement of the outcomes is done ex post facto. Important as ex post results certainly are to judge the degree of success of the full execution of the portfolio, they are not, per se, appropriate for managers to act upon and take steps, ex ante, in order to increase the chances of success. Besides, lagging indicators (those measured after the fact), managers also need leading indicators (those upon which they can act in order to try to obtain a given consequence). So, it is necessary to distinguish between (degree of) success of a portfolio (i.e., its ex post results) and (degree of) success of portfolio management.

From an academician's viewpoint, measuring the degree of success of (the process of) portfolio management by the consequences accruing from the portfolio's deliverables would lead to undesirable circular reasoning. That is, (i) a portfolio will be evaluated as successful if it leads to satisfactory (ex post) results for the company and (ii) a company will tend to obtain better results the better its portfolio management process is. However, in order to test theory about expected antecedents of portfolio management (e.g., organization structure, organizational culture) and the impact of portfolio management on organizational variables (such as business performance or employees' motivation), it is necessary to measure aspects that are intrinsic to portfolio management and defined independently of its antecedents and consequences.

Given Thomas, Delisle, Jugdev and Buckle's (2002) contention that value of project management is not generally recognized outside the project management community, particularly at senior levels, and also Aubry and Hobbs' (2011:3) complaint that project management "contribution to performance is still not acknowledged outside the group of professionals who believe in project management", it becomes critical to properly measure quality (of project management and) of portfolio management, so that practitioners can have valid tools to guide their efforts.

\section{CONCLUSIONS}

We conducted 21 interviews with experienced managers, consultants and academics experts in project and portfolio management in Brazil. These practitioners represent a diversity of organizational types and provide a fairly comprehensive picture of portfolio management. We applied a mixed research combining grounded data and literature inputs to unveil the dimensions pertaining to portfolio formation and execution (these dimensions should be regarded as preliminary and need to undergo further theoretical and empirical 
scrutiny in future studies). We learned from these informants that portfolio management is highly associated with developing: a) a structured process for portfolio formation, that is, use of appropriate criteria for project selection; and b) attentive portfolio execution, including flexibility to adapt to changes on resource distribution patterns without generating great conflicts and a governance configuration that involves both top management commitment as well as a capability to cope with project portfolio complexities. These aspects are seldom addressed by current prescriptive models, but they showed to be important features of portfolio management in practice.

This study may be particularly important in the context of Brazilian firms, and of Latin American firms in general, because there is anecdotal evidence that Brazilians would be more prone to improvisation and to "learning by doing" than to formal planning and controlling. By obtaining evidence from several Brazilian firms that are in fact actively involved in project management and by eliciting their currently self-recognized strengths and gaps in portfolio management, we have advanced a preliminary insights that shall be useful both for scholars and for managers.

Our intense comparison analysis enabled us to address the interplay between data and insights, which enhanced internal validity through verification of the inductive model; however, the descriptive nature of the study urges for a posterior verification in a larger sample. Besides, in spite of the precautions taken, our findings results of the interviews may have been biased by the inadvertent actions (words, gestures) of the interviewer that might hamper spontaneity of the interviewee or by social desirability bias on the part of the interviewee. Despite its limitations, this study can be regarded as a first step in providing both managers and scholars with a descriptive model of portfolio management that, after proper empirical refinement, can be used to test the relationship of portfolio management with its antecedents and consequences.

\section{REFERENCES}

ARTTO, A. et al. Project strategy: strategy types and their contents in innovation projects. International Journal of Managing Projects in Business, v. 1, n. 1, p. 49-70, 2008.

AUBRY, M.; HOBBS, B. A fresh look at the contribution of project management to organizational performance. Project Management Journal, feb. 3-16, 2011.

BIBLE, M. J.; BIVINS, S. S. Evaluating strategic project and portfolio performance. Journal of Project, Program \& Portfolio Management, v. 3, n. 1, p. 10-30, 2012. 
BOLLEN, K. A. Structural equations with latent variables. New York: John Wiley \& Sons, 1989.

COOKE-DAVIES, T. The "real"' success factors on projects. International Journal of Project Management, v. 20, p. 185-190, 2002.

COOPER, R.; EDGETT, S. Portfolio management in new product development: lessons from the leaders - I. Research Technology Management, v. 40, n. 5, p. 1-17, 1997.

COOPER, R.; EDGETT, S.; KLEINSCHMIDT, E. Porfolio management for new product development: results of an industry practices study. R\&D Management, v. 31, n. 4, p. 361$380,2001$.

$\therefore$.;___ Doing it right: winning with new products. Working Paper $\mathbf{n}^{\mathbf{0}} \mathbf{1 0}$, Product Development Institute, 2000a.

$\therefore$;___ New problems, new solutions: making portfolio management more effective. Research Technology Management, v. 43, n. 2, p. 18-33, $2000 \mathrm{~b}$.

COPERTARI, L. Selecting projects in a portfolio using risk and ranking. Journal of Project, Program \& Portfolio Management, 2(1):10-28, 2011.

DAI, C.; WELLS, W. An exploration of project management features and their relationship to project performance. International Journal of Project Management, v. 22, p. 523-532, 2004.

DENZIN, N. The research act: a theoretical introduction to sociological methods. Piscataway, NJ: Aldine Transaction, 2009.

DIETRICH, P.; LEHTONEN, P. Successful management of strategic intentions through multiple projects: Reflections from empirical study. International Journal of Project Management, v. 23, n. 5, p. 386-391, 2005.

DVIR, D.; LECHLER, T. Plans are nothing, changing plans is everything: the impact of changes on project success. Research Policy, v. 33, n. 1, p. 1-15, 2004.

DYE, L.; PENNYPACKER, J. Introduction to project portfolio management. In: . (Eds.). Project portfolio management: selecting and prioritizing projects for competitive advantage. West Chester, PA: Center for Business Practices (PA), 1999.

FLICK, U. An introduction to qualitative research. 3. ed. Sage Publications Ltd, 2006.

GRAY, C.; LARSON, E. Project management: the managerial process. Boston, MA: McGraw-Hill Professional, 2005.

GRUNDY, T. Strategy implementation through project management. London: Hawksmere. 2001.

HINKIN, T. A brief tutorial on the development of measures for use in survey questionnaires. Organizational Research Methods, v. 1, n. 1, p. 104 121, 1998.

HREBINIAK, L. Making strategy work: leading effective execution and change. Pearson 
Prentice Hall, 2005.

JUDGEV, K.; MÜLLER, R. A retrospective look at our evolving understanding of project success. Project Management Journal, Dez. 2005.

KAPLAN, R.; NORTON, D. The balanced scorecard: translating strategy into action. Harvard Business Review Press, 1996.

KERZNER, H. Project management: a system approach to planning, scheduling and controlling. New York: John Wiley \& Sons, 2003.

LACERDA R.; ENSSLIN L.; ENSSLIN, S. A performance measurement framework in portfolio management: a constructivist case. Management Decision, v. 49, n. 4, p. 648-668, 2011.

LEVINE, H. Project portfolio management: a practical guide to selecting projects, managing portfolios and maximizing benefits. New York: John Wiley \& Sons, Inc, 2005.

MACKENZIE, S. The dangers of poor construct conceptualization. Journal of the Academy of Marketing Science, v. 31, n. 3, p. 323-326, 2003.

MARTINSUO, M.; LEHTONEN, P. Role of single-project management in achieving portfolio management efficiency. International Journal of Project Management, v. 25, p. 56-65, 2007.

MEREDITH, J.; MANTEL, S. Project management: a managerial approach. New York: Wiley \& Sons, 2000.

MESKENDAHL, S. The influence of business strategy on project portfolio management and its success: a conceptual framework. International Journal of Project Management, v. 28, p. 807-817, 2010.

MILES, M.; HUBERMAN, A. An expanded sourcebook qualitative data analysis. London: Sage Publication, 1994.

MILLER, R.; MARTINSUO, M.; BLOMQUIST, T. Project portfolio control and portfolio management performance in different contexts. Project Management Journal, v. 39, n. 3, p. 28-42, 2008.

MINTZBERG, H.; WATERS, J. Of strategies, deliberated and emergent. Strategic Management Journal, v. 6, p. 257-272, 1985.

MORGAN, M.; LEVITT, R.; MALEK, W. Executing your strategy: how to break it down and get it done. Harvard Business School Press, 2007.

MORRIS, P.; JAMIESON, A. Translating corporate strategy into project strategy: realizing corporate strategy through project management. Newton Square, PA: Project Management Institute Inc., 2004.

NOBLE, C. The eclectic roots of strategy implementation research. Journal of Business Research, v. 45, p. 119-134, 1999. 
PATTON, M. Q. Qualitative research \& evaluation methods. Thousand Oaks, CA: Sage, 2002.

PETER, J. Construct validity: a review of basic issues and marketing practices. Journal of Marketing Research, v. 18, n. 2, p. 133-145, 1981.

PMI. Project Management Institute. The standard for portfolio management. 3. ed. Newton Square, PA: Project Management Institute, Inc., 2013

Project Portfolio Management (PPM): the natural evolution of project management. PMI Virtual Library, 2011.

A guide to project management body of knowledge: PMBoK. 4. ed. Newton Square, PA: Project Management Institute, Inc., 2008.

PORTER, M.; MONTGOMERY, C. Introduction. In: (Eds.). Strategy: seeking and securing competitive advantage. Harvard Business Review Press, 1991.

SHENHAR, A. Strategic project leadership: toward a strategic approach to project management. R\&D Management, v. 34, n. 5, p. 569-578, 2004.

SHENHAR, A. et al. Project success: a multidimensional strategic concept. Long Range Planning, v. 34, p. 699-725, 2001.

SEIDMAN, I. Interviewing as qualitative research: a guide for researchers in education and the social sciences. 3. ed. New York: Teachers College Press, 2006.

SRIVANNABOON, S.; MILOSEVIC, D. Linking Project Management with Business Strategy. Project Management Journal, v. 37, n. 5, p. 88-97, $2006 a$.

.;. A two-way influence between strategy and project management.

International Journal of Project Management, v. 24, n. 6, p. 493-505, 2006b.

STRAUSS, A.; CORBIN, J. Basics of qualitative research: techniques and procedures for developing grounded theory. 2. ed. Thousand Oaks, California: Sage Publications, 1998.

SUDDABY, R. From the editors: what grounded theory is not. Academy of Management Journal, v. 49, n. 4, p. 633-642, 2006.

THOMAS, J. L. et al. Selling project management to senior executives: framing the moves that matter. Newtown Square, PA: Project Management Institute, 2002. 